\title{
Quercetin alleviates cell apoptosis and inflammation via the ER stress pathway in vascular endothelial cells cultured in high concentrations of glucosamine
}

\author{
XIAXIA CAI ${ }^{1,2 *}$, LEI BAO $^{3 *}$, YE DING $^{4}$, XIAOQIAN DAI ${ }^{1}$, ZHAOFENG ZHANG $^{1}$ and YONG LI $^{1}$ \\ ${ }^{1}$ Department of Nutrition and Food Hygiene, School of Public Health, Peking University, Beijing 100191; \\ ${ }^{2}$ School of Public Health, Beijing Key Laboratory of Environment Toxicology, Capital Medical University, Beijing 100069; \\ ${ }^{3}$ Department of Clinical Nutrition, Peking University International Hospital, Beijing 100191; ${ }^{4}$ Department of Maternal, \\ Child and Adolescent Health, School of Public Health, Nanjing Medical University, Nanjing, Jiangsu 211166, P.R. China
}

Received August 24, 2015; Accepted November 3, 2016

DOI: $10.3892 / \mathrm{mmr} .2016 .6054$

\begin{abstract}
Glucosamine is a possible cause of vascular endothelial injury in the initial stages of atherosclerosis, through endoplasmic reticulum (ER) stress resulting in fatty streaks in the vascular wall. Quercetin is an anti-diabetic and cardiovascular protective agent that has previously been demonstrated to reduce ER stress in human umbilical vein endothelial cells (HUVECs). The present study aimed to investigate whether quercetin prevents glucosamine-induced apoptosis and inflammation via ER stress pathway in HUVECs. The effect of quercetin on cell viability, apoptosis, and protein expression levels of inflammatory cytokines and ER stress markers was investigated in glucosamine-supplemented HUVECs. Quercetin was demonstrated to protect against glucosamine-induced apoptosis, improved cell viability, and inhibited expression of pro-inflammatory factors and endothelin-1. Quercetin treatment also reduced the expression levels of glucose-regulated protein 78, phosphorylated protein
\end{abstract}

Correspondence to: Professor Yong Li, Department of Nutrition and Food Hygiene, School of Public Health, Peking University, 38 Xueyuan Road, Beijing 100191, P.R. China

E-mail: liyongbmu@163.com

*Contributed equally

Abbreviations: AS, atherosclerosis; CHD, coronary heart disease; CHOP, C/EBP homologous protein; DMEM, Dulbecco's modified Eagle's medium; DMSO, dimethyl sulfoxide; ET-1, endothelin-1; FBS, fetal bovine serum; GRP78, glucose regulated protein 78; HBP, hexosamine biosynthesis pathway; HUVEC, human umbilical vein endothelial cell; ICAM-1, intercellular adhesion molecule-1; JNK, c-Jun N-terminal kinase; PERK, protein kinase-like ER kinase; TUNEL, terminal-deoxynucleotidyl transferase mediated dUTP nick end labeling; VCAM-1, vascular cell adhesion molecule-1

Key words: apoptosis, ER stress, glucosamine, quercetin, vascular endothelial cell kinase-like ER kinase, phosphorylated c-Jun N-terminal kinase and C/EBP homologous protein. In conclusion, quercetin may have auxiliary therapeutic potential against glucosamine-induced cell apoptosis and inflammation, which may be partially due to alleviation of ER stress.

\section{Introduction}

Diabetes is a 'coronary heart disease (CHD) equivalent' disease, as epidemiological data has previously demonstrated that patients with diabetes without any prior evidence of CHD are at greater risk of death from CHD than nondiabetic patients with prior evidence of CHD $(1,2)$. Atherosclerosis (AS) is a disease of arterial lipid deposition leading to a number of biological responses, including a chronic, macrophage-dominated inflammatory reaction (3), and is the pathological basis of CHD. The hexosamine biosynthesis pathway (HBP), a normal pathway for glucose metabolism, is activated excessively in patients with diabetes, resulting in increased cellular glucosamine (4). Endoplasmic reticulum (ER) is a membranous network to synthesize, modify, fold and assemble proteins. When the ER function, particularly folding capacity, is challenged, the unfolded protein response (UPR) is executed as a protective mechanism in ER. Failure of this mechanism to fold newly synthesized proteins shows unique damage to the cell and is termed 'ER stress' $(5,6)$. Numerous studies have highlighted that ER stress may link hyperglycemia to AS $(4,7,8)$. Important ER stress markers, including protein kinase-like ER kinase (PERK), glucose regulated protein 78 (GRP78) and $\mathrm{C} / \mathrm{EBP}$ homologous protein (CHOP), were expressed in the arterial wall of streptozotocin-induced hyperglycemic apolipoprotein (apoE)-deficient mice (4). Glucosamine levels and the expression of GRP78 were increased following hyperglycemia and prior to the early stages of fatty streak formation in aortic endothelial cells of hyperglycemic apoE $E^{-/-}$mice (7). In vitro studies have demonstrated that incubation of hepatic cells (9) and adipocytes (10) with $5 \mathrm{mM}$ glucosamine resulted in lipid accumulation, impaired insulin-stimulated glucose transport and elevated levels of ER stress markers. High-dose glucosamine may, therefore, increase the inflammatory 
response and induce lipid metabolic abnormalities, further aggravate endothelial cell injury and, ultimately, accelerate the development of AS (11). However, as an effective nutritional supplement in human osteoarthritis, orally administered glucosamine sulfate demonstrated an anti-atherosclerotic effect in rabbits with AS aggravated by chronic arthritis (12). Incubation of human umbilical vein endothelial cells (HUVECs) with $0.5 \mathrm{mM}$ glucosamine has previously been demonstrated to inhibit tumor necrosis factor- $\alpha$-induced inflammation (13), and glucosamine significantly suppressed mesangial cell viability at a concentration of $15 \mathrm{mM}$ (14). The concentration of glucosamine that induces cell injury, and the mechanism by which ER stress leads to cell injury under conditions of high glucosamine is, therefore, unclear.

Persistent and serious ER stress causes apoptosis, which results in a series of pathophysiological changes, including increased phosphorylation of protein kinase-like ER kinase (PERK), a trans-ER-membrane factor, which results in increased levels of C/EBP homologous protein (CHOP) (15). $\mathrm{CHOP}$ can induce transcriptional activation of endoplasmic reticulum oxidoreductase-1 (Erol $\alpha)$ and Erol $\alpha$ can activate the inositol triphosphate receptor (IP3R). IP3R can subsequently stimulate excess $\mathrm{Ca}^{2+}$ transport from the ER to the mitochondria, triggering cell death (16). CHOP also can inhibit Bcl-2 transcription directly to initiate apoptosis $(16,17)$. Diabetes and AS are characterized by low-grade, chronic inflammation $(11,18)$. Previous studies have suggested that c-Jun N-terminal kinase (JNK) linked ER stress and apoptosis, and was also the link between ER stress and inflammation (19) and insulin resistance (20). Thus, the use of anti-inflammatory and anti-apoptotic agents against inflammation, apoptosis and ER stress may contribute to the prevention of AS in patients with diabetes.

Quercetin is a widely distributed plant flavonoid, which has been reported to possess biological activities against cardiovascular disease and associated risk factors (21). Epidemiological (22) and clinical studies (23) suggest that there is an inverse correlation between flavonoid supplementation and cardiovascular risk, and numerous clinical and animal studies have reported the anti-inflammatory and anti-oxidative functions of quercetin (23-29). Furthermore, quercetin alleviates AS development in rabbits (30) and mice (31). Quercetin has also been demonstrated to control blood glucose levels, and improve glucose uptake and insulin sensitivity in vitro $(32,33)$. Suganya et al (34) also demonstrated that quercetin prevents tunicamycin-induced ER stress through modulation of GRP78 and CHOP levels in endothelial cells. Chao et al (35) demonstrated that the inhibitory effect of $300 \mathrm{nM}$ quercetin sulfate/glucuronide (the metabolite of quercetin in blood) on apoptosis and JNK activity under conditions of high glucose was similar to that of $100 \mu \mathrm{M}$ ascorbic acid, an antioxidant commonly used to improve vascular function. However, limited research has been performed to investigate the effect of quercetin on ER stress under diabetic conditions, and the relevant mechanisms.

As vascular endothelial cell injury is the initial step of AS (36), the present study hypothesized that high levels of glucosamine, a HBP metabolite, would mimic the early stages of vascular endothelial cell injury in diabetes. The present study aimed to investigate the protective effect of quercetin on inflammation and apoptosis in HUVECs treated with high-dose glucosamine, and to determine whether this protective effect was associated with inhibition of ER stress.

\section{Materials and methods}

Reagents and antibodies. High-glucose Dulbecco's modified Eagle's medium (DMEM) and fetal bovine serum (FBS) were obtained from Gibco; Thermo Fisher Scientific, Inc. (Waltham, MA, USA). Trypsin, dimethyl sulfoxide (DMSO) and MTT were purchased from MAC Gene Technology (Beijing, China; http://macgene.com/cart/). Quercetin, ( $\geq 95 \%$, HPLC), $N$-acetyl-D-glucosamine and tunicamycin (from Streptomyces spp.) were purchased from Sigma-Aldrich, Merck Millipore (Darmstadt, Germany). Endothelial cell growth supplement (ECGS; cat. no. 1052) was obtained from Sciencell Research Laboratories (Carlsbad, CA, USA). Human soluble intercellular adhesion molecule-1 (ICAM-1)/CD54 Quantikine ELISA kit (cat. no. DCD540), human soluble vascular cell adhesion molecule-1 (VCAM-1)/CD106 Quantikine ELISA kit (cat. no. DVC00) and endothelin-1 (ET-1) Quantikine ELISA kit (cat. no. DET100) were obtained from R\&D Systems, Inc. (Minneapolis, MN, USA). One-step terminal-deoxynucleotidyl transferase dUTP nick end labeling (TUNEL) apoptosis in situ detection kit was purchased from Nanjing KeyGen Biotech Co., Ltd. (Nanjing, China). Polyclonal antibody to GRP78 (cat. no. 3183) and monoclonal antibodies to CHOP (cat. no. 2895), PERK (cat. no. 5683) and $\beta$-actin (cat. no. 4970) were purchased from Cell Signaling Technology, Inc. (Danvers, MA, USA). Phosphorylated (p)-PERK (cat. no. sc-32577), JNK D-2 (cat. no. sc-7345), p-JNK G-7 (cat. no. sc-6254), VCAM-1 H276 (cat. no. sc-8304) and caspase-3 (cat. no. sc-7148) antibodies were purchased from Santa Cruz Biotechnology, Inc. (Dallas, TX, USA). Goat anti-mouse immunoglobulin G (IgG; $\mathrm{H}+\mathrm{L}$ )-horseradish peroxidase (HRP; cat. no. ZB-2305), goat anti-rabbit IgG (H+L)-HRP (cat. no. ZB-2301) and goat anti-rat IgG (H+L)-HRP (cat. no. ZB-2307) antibody conjugates were obtained from OriGene Technologies, Inc. (Beijing, China).

Cell culture and treatments. HUVECs (no. CRL-1730) were obtained from the American Type Culture Collection (Manassas, VA, USA). Cells were cultured in high-glucose DMEM supplemented with $10 \% \mathrm{FBS}$ and $0.05 \mathrm{mg} / \mathrm{ml}$ ECGS at $37^{\circ} \mathrm{C}$ in a humidified, $5 \% \mathrm{CO}_{2}$ atmosphere. Cells were subcultured in culture flasks (Corning Incorporated, Corning, NY, USA) and passaged every 3 days. The cells were used at their fourth passage. All experiments were performed at the logarithmic phase of cell growth, and it took $24 \mathrm{~h}$ to grow to logarithmic phase of cell. At $70 \%$ confluence, the cells were cultured for $12 \mathrm{~h}$ in serum-free medium. The cells incubated in normal medium (high-glucose DMEM with 10\% FBS) for $24 \mathrm{~h}$ were used as the vehicle group and other HUVECs in high-glucose DMEM and 10\% FBS were subsequently divided into seven groups: 'HG' group cells were cultured in $15 \mathrm{mM}$ glucosamine; 5, 10, 20 and $50 \mu \mathrm{M}$ quercetin group cells were cultured in $15 \mathrm{mM}$ glucosamine and various doses of quercetin $(5,10,20$ and $50 \mu \mathrm{M}$, respectively); mannitol group cells were cultured in $15 \mathrm{mM}$ mannitol (subsequently referred to as osmolarity control); and another HUVECs were cultured 
in high-glucose DMEM and 10\% FBS with $50 \mu \mathrm{M}$ quercetin (subsequently referred to as quercetin control). The aforementioned cells were cultured for a further $24 \mathrm{~h}$. In another group of experiments, the cells were treated with $5 \mu \mathrm{g} / \mathrm{ml}$ tunicamycin for $4 \mathrm{~h}$ as positive control. The concentration of quercetin used in previous in vitro studies into cardiovascular diseases ranged from $10-80 \mu \mathrm{M}(30,35,37)$, while the highest concentration of quercetin observed in murine plasma was $27.6 \mu \mathrm{M}$ (31). However, the highest concentration of quercetin observed in human plasma was $4.1 \mu \mathrm{M}$, which was observed $10 \mathrm{~h}$ after ingestion of $1,095 \mathrm{mg}$ quercetin (38). Due to the limited availability of information regarding quercetin cell cytotoxicity, concentrations of $0,5,10,20$ and $50 \mu \mathrm{M}$ quercetin were utilized in the present study.

MTT assay. Cell viability was detected by MTT assay as previously described $(14,37,39)$. Following treatment in 96-well plates for $24 \mathrm{~h}, 100 \mu \mathrm{l} \mathrm{MTT}(1 \mathrm{mg} / \mathrm{ml})$ solutions was added to each well, then cells were incubated for $4 \mathrm{~h}$ at $37^{\circ} \mathrm{C}$. The MTT solution was then discarded, and $100 \mu 1 \mathrm{DMSO}$ was added to each well. Absorbance at $490 \mathrm{~nm}$ was then read using a microplate reader (Bio-Rad Laboratories, Inc., Hercules, CA, USA). Values were normalized to those of cells in the vehicle group.

TUNEL assays. DNA fragmentation was observed by TUNEL as previously described (14). Cells were treated on cover slips in 6 -well plates at a density of $3 \times 10^{5}$ cells $/ \mathrm{ml}$. Following intervention, cells were fixed in $4 \%$ paraformaldehyde for $30 \mathrm{~min}$ at room temperature, then washed 3 times in phosphate-buffered saline (PBS). Triton X-100 (1\%) was added for 3-5 min to promote permeability, then cells were washed again in PBS. Cells were blocked with $3 \% \mathrm{H}_{2} \mathrm{O}_{2}$ for $10 \mathrm{~min}$ at room temperature and incubated with $50 \mu \mathrm{l}$ terminal deoxynucleotidyl transferase enzyme reaction solution (45 $\mu 1$ equilibration buffer, $1 \mu$ l tetramethyl rhodamine isothiocyanate-5-dUTP and $4 \mu \mathrm{l}$ terminal deoxynucleotidyl transferase enzyme) for $60 \mathrm{~min}$ at $37^{\circ} \mathrm{C}$ in the dark. Fluorescence intensity was measured using an Eclipse TE2000-S fluorescence microscope (Nikon Corporation, Tokyo, Japan) using wavelengths of $543 \mathrm{~nm}$ (excitation) and $571 \mathrm{~nm}$ (detection). Red fluorescence indicated the presence of apoptotic cells. Apoptotic cells were counted in three random high-power fields (HPF) of three different slides.

ELISA. Following 24-h treatment in 24-well plates, concentrations of VCAM-1, ICAM-1, and ET-1 were determined by ELISA according to manufacturer's instructions $(40,41)$. Supernatant was collected and centrifuged at $1,000 \mathrm{x} \mathrm{g}$ for $10 \mathrm{~min}$. The lyophilised quantikine standard was reconstituted in distilled water and serially diluted 1:2 in kit standard diluent to produce standard curve samples. Prior to the experiment, the samples required a 5-fold dilution (a suggested 5-fold dilution is $20 \mu \mathrm{l}$ of samples and $80 \mu \mathrm{l}$ of Calbrator Diluent). A total of $100 \mu 1$ human ICAM-1 or VCAM-1 conjugate was added to each well. Next, $100 \mu \mathrm{l}$ standard, control (recombinant human sICAM-1 and VCAM-1 provided with the kits as positive controls) and experimental samples were added to the designated wells in a 96-well polystyrene microplate (provided with the kit). The plate was covered with the adhesive strip provided and incubated for $1.5 \mathrm{~h}$ at room temperature on a horizontal orbital microplate shaker $\left(0.12^{\prime \prime}\right.$ orbit). Following this, the wells were washed with $400 \mu \mathrm{l}$ wash buffer three times. After the final wash, for ET-1, $150 \mu \mathrm{l}$ of assay diluent was added to each well. A total of $75 \mu \mathrm{l}$ standard, control (Synthetic Endothelin-1 provided with the kits as positive controls) and experimental samples were subsequently added to each well. The plate was covered with an adhesive strip and incubated for $1 \mathrm{~h}$ at room temperature on a horizontal orbital microplate shaker. The plates were washed as before four times. The plates were the incubated for $3 \mathrm{~h}$ at room temperature with $200 \mu \mathrm{l}$ HRP-conjugated secondary antibody. The wells were washed, as before. Substrate solution (200 $\mu 1$ for ICAM-1 and ET-1, $100 \mu \mathrm{l}$ for VCAM-1, chromogen solution A and chromogen solution B were mixed together in equal volumes) was then added to each well, and the plates were protected from light and incubated for $30 \mathrm{~min}$ at room temperature. Finally, $50 \mu \mathrm{l}$ stop solution was added to the wells and the colored products were measured at $450 \mathrm{~nm}$ within $30 \mathrm{~min}$, with the wavelength correction set at $570 \mathrm{~nm}$, on a multi-detection microplate reader (Bio-Rad Laboratories, Inc.). The standard curve, experimental and control samples were assayed in duplicate.

Western blotting. Cells from each group were treated for $24 \mathrm{~h}$ in $10 \mathrm{~mm}$ culture dishes, and then cells $\left(1 \times 10^{7}\right)$ were washed three times in ice-cold PBS, then lysed for $30 \mathrm{~min}$ in lysis buffer [20 mM Tris- $\mathrm{HCl}$ (pH 7.5), $150 \mathrm{mM} \mathrm{NaCl}, 1 \mathrm{mM} \mathrm{Na}_{2}$ EDTA, $1 \mathrm{mM}$ EGTA, $1 \mathrm{mM} \mathrm{Na} \mathrm{VO}_{4}, 11 \mathrm{mM} \beta$-mercaptoethanol, $0.1 \%$ Triton X-100, $2.5 \mathrm{mM} \mathrm{Na} \mathrm{P}_{2} \mathrm{O}_{7}, 1 \mu \mathrm{g} / \mathrm{ml}$ leupeptin, $1 \mu \mathrm{g} / \mathrm{ml}$ aprotinin, and $1 \mu \mathrm{g} / \mathrm{ml}$ pepstatin] with $1 \mathrm{mM}$ phenylmethylsulfonyl fluoride (Sigma-Aldrich) $(14,39)$. Lysates were centrifuged at $12,000 \mathrm{x}$ g for $5 \mathrm{~min}$ at $4^{\circ} \mathrm{C}$, and the concentration of total protein in the supernatant was quantified by bicinchoninic acid protein assay. Protein samples $(20 \mu \mathrm{g})$ were separated by sodium dodecyl sulfate-polyacrylamide gel electrophoresis on 8,10 or $12 \%$ gels, then transferred onto $0.45 \mu \mathrm{m}$ polyvinylidene fluoride membranes (EMD Millipore, Billerica, MA, USA). The membranes were blocked with 5\% (v/v) nonfat dried milk in Tris-buffered saline containing $0.05 \%$ Tween-20 (TBS-T) at room temperature for $1 \mathrm{~h}$, then incubated with the primary antibody at $4^{\circ} \mathrm{C}$ overnight. GRP78, CHOP and PERK antibodies were used at a dilution of 1:1,000, $\beta$-actin antibody at 1:2,000, and VCAM-1, p-PERK, JNK, p-JNK and caspase-3 antibodies at 1:200. Membranes were then washed 3 times in TBS-T, and incubated in HRP-conjugated secondary antibodies $(1: 4,000)$ for $1 \mathrm{~h}$ at $37^{\circ} \mathrm{C}$. Protein complexes were detected using enhanced chemiluminescence western blotting detection reagents (MAC Gene Technology Ltd.). Digital images of the blots were analyzed using Image Pro Plus 6.0 software (Media Cybernetics, Inc., Rockville, MD, USA).

Statistical analysis. All experimental data are presented as the mean \pm standard deviation of at least three independent experiments. One-way analysis of variance was performed using SPSS 13.0 for Windows (SPSS, Inc., Chicago, IL, USA) to compare variances. If variances were equal, Bonferroni multiple comparison tests were performed using with SPSS 13.0; otherwise, Tamhane's T2 test was performed by SPSS 13.0. $\mathrm{P}<0.05$ was considered to indicate a statistically significant difference. 


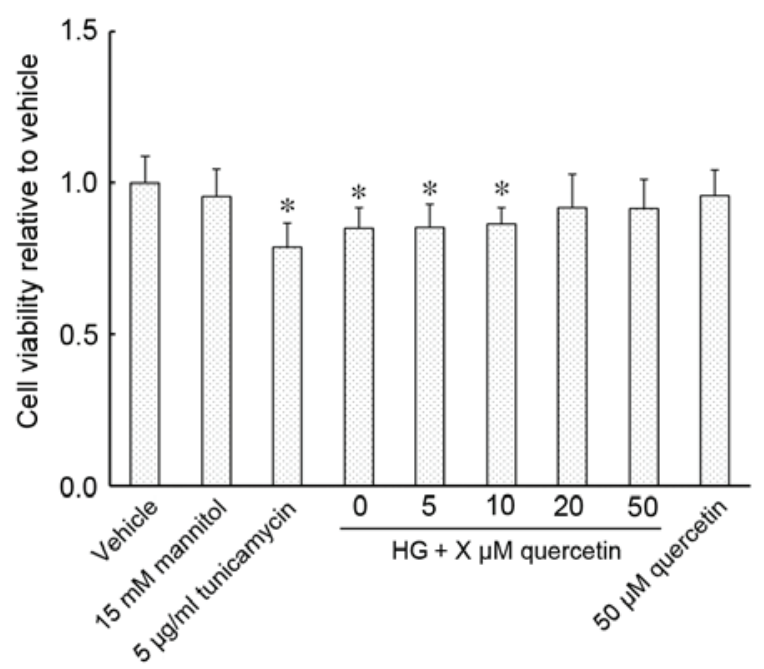

Figure 1. Effect of quercetin on human umbilical vein endothelial cell viability in high glucosamine conditions. Viability of cells cultured in $\mathrm{HG}$, with $0,5,10,20$ and $50 \mu \mathrm{M}$ quercetin was assessed by 3-4,5-dimethylthiazol-2-yl)-2,5-diphenyltetrazolium bromide (MTT) assay. Data are presented as the mean \pm standard deviation of 6 replicates. ${ }^{*} \mathrm{P}<0.05$ vs. vehicle group. HG, $15 \mathrm{mM}$ glucosamine.

\section{Results}

Effect of quercetin on the viability of HUVECs treated with high-dose glucosamine. Exposure of HUVECs to an ER stress inducer, tunicamycin, and $15 \mathrm{mM}$ glucosamine resulted in a significant decrease in cell viability compared with the vehicle control $(\mathrm{P}<0.001$ for $5 \mu \mathrm{g} / \mathrm{ml}$ tunicamycin group and
$\mathrm{P}=0.002$ for HG group; Fig. 1). Cell viability was restored in cells cultured in $15 \mathrm{mM}$ glucosamine following treatment with 20 or $50 \mu \mathrm{M}$ quercetin, with no significant changes detected compared with vehicle (Fig. 1). Cell viability compared with the vehicle control was not significantly altered in cells treated with $50 \mu \mathrm{M}$ quercetin, whether cultured with or without $15 \mathrm{mM}$ glucosamine (Fig. 1).

Effect of quercetin on the apoptosis of HUVECs treated with high-dose glucosamine. Fig. 2 demonstrates TUNEL-positive HUVECs (strong red fluorescence) that are undergoing apoptosis. There was no significant difference observed between the vehicle and mannitol-treated groups (Fig. 2). Treatment with $15 \mathrm{mM}$ glucosamine resulted in increased apoptosis compared with the vehicle group $(\mathrm{P}<0.001$; Fig. 2). However, a dose-dependent effect was observed in cells also treated with quercetin, with no significant difference in the number of TUNEL-positive cells when treated with 10 and $20 \mu \mathrm{M}$ quercetin compared with the vehicle control (Fig. 2).

Effect of quercetin on expression of markers of endothelial dysfunction in HUVECs treated with high-dose glucosamine. Stimulation of HUVECs with $15 \mathrm{mM}$ glucosamine resulted in significantly increased expression of ICAM-1 and ET-1 compared with the vehicle control group ( $\mathrm{P}=0.009$ for ICAM-1 and $\mathrm{P}=0.049$ for ET-1, respectively; Fig. 3A and B, respectively). Following quercetin treatment, ICAM-1 expression was decreased significantly at all concentrations of quercetin treatment compared with the HG group $(\mathrm{P}=0.016, \mathrm{P}<0.001$ and $\mathrm{P}=0.022$ for $5,10,20 \mu \mathrm{M}$ quercetin, respectively; Fig. 3A), and demonstrated no significant difference compared with the

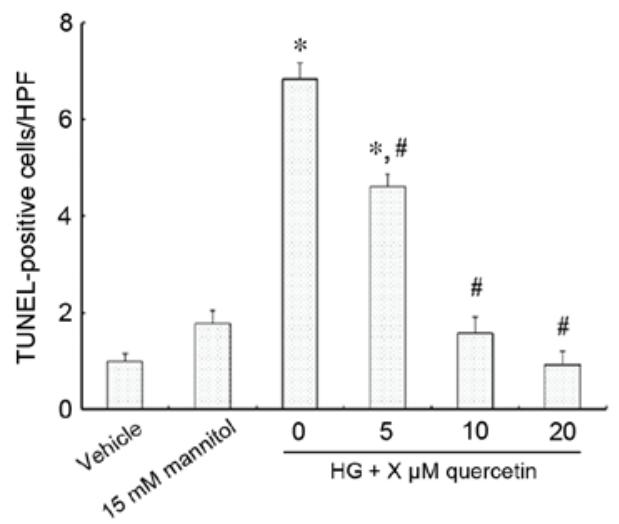

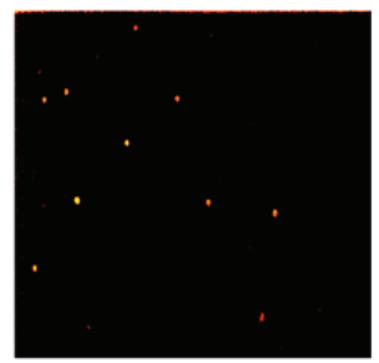

Vehicle

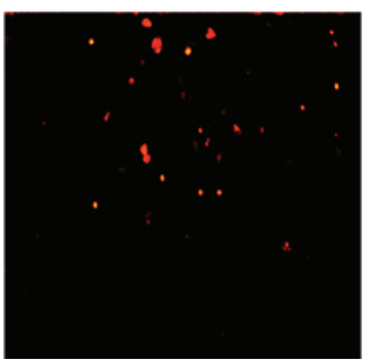

10

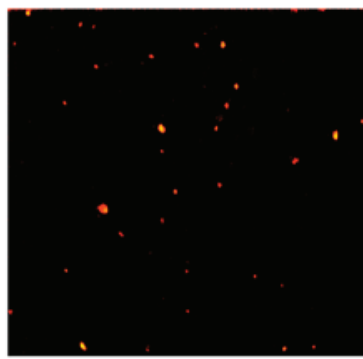

$15 \mathrm{mM}$ mannitol

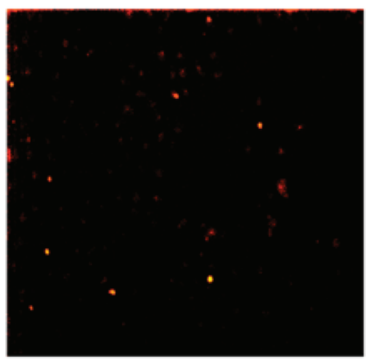

20

$\mathrm{HG}+\mathrm{X} \mu \mathrm{M}$ quercetin

Figure 2. Apoptotic effect of quercetin on human umbilical vein endothelial cells cultured in high-dose glucosamine. Apoptosis was measured by TUNEL staining, with representative images of TUNEL stained cells in each condition shown (original magnification, x400). Apoptotic cells were counted in three random high-power fields (HPF) of three different slides. Data are presented as the mean \pm standard deviation of 3 replicates. * $<<0.05$ vs. vehicle group. ${ }^{\#} \mathrm{P}<0.05$ vs. HG group. TUNEL, terminal deoxynucleotidyl transferase-mediated dUTP nick-end labeling; HPF, high power field; HG, 15 mM glucosamine. 
A

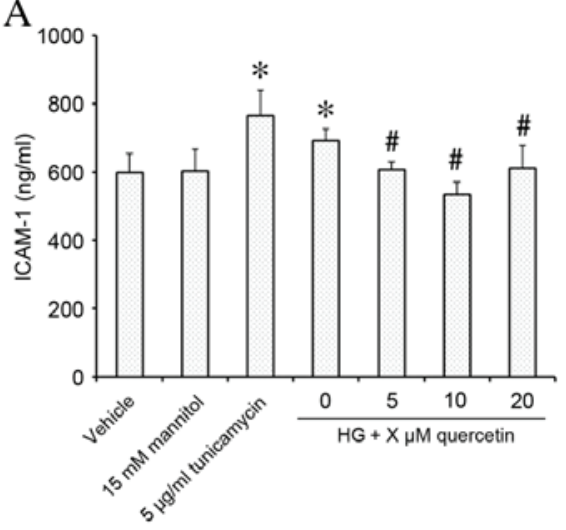

$\mathrm{B}$

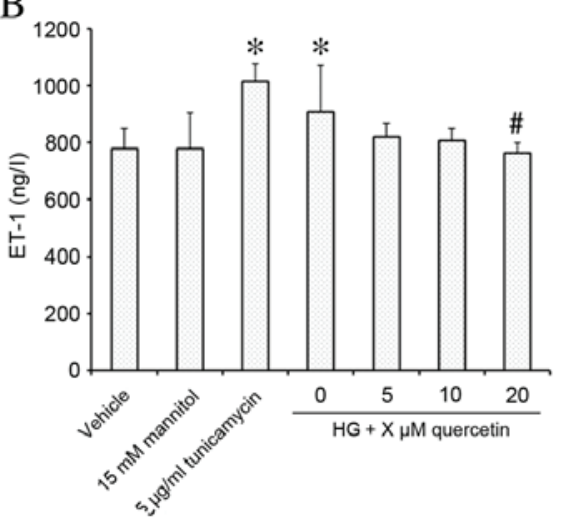

C

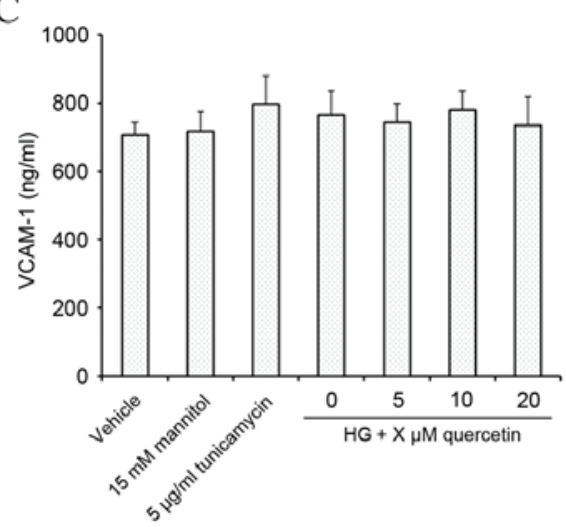

Figure 3. Effects of quercetin on expression of markers of endothelial dysfunction. Protein expression levels of (A) ICAM-1, (B) ET-1 and (C) VCAM-1 in the supernatant of human umbilical vein endothelial cells treated with high-dose glucosamine were determined by enzyme-linked immunosorbent assay. Data are presented as the mean \pm standard deviation of 6 replicates. ${ }^{*} \mathrm{P}<0.05$ vs. vehicle group, ${ }^{~} \mathrm{P}<0.05$ vs. HG group. ICAM-1, intercellular adhesion molecule-1; ET-1, endothelin-1; VCAM-1, vascular cell adhesion molecule-1; HG, 15 mM glucosamine.
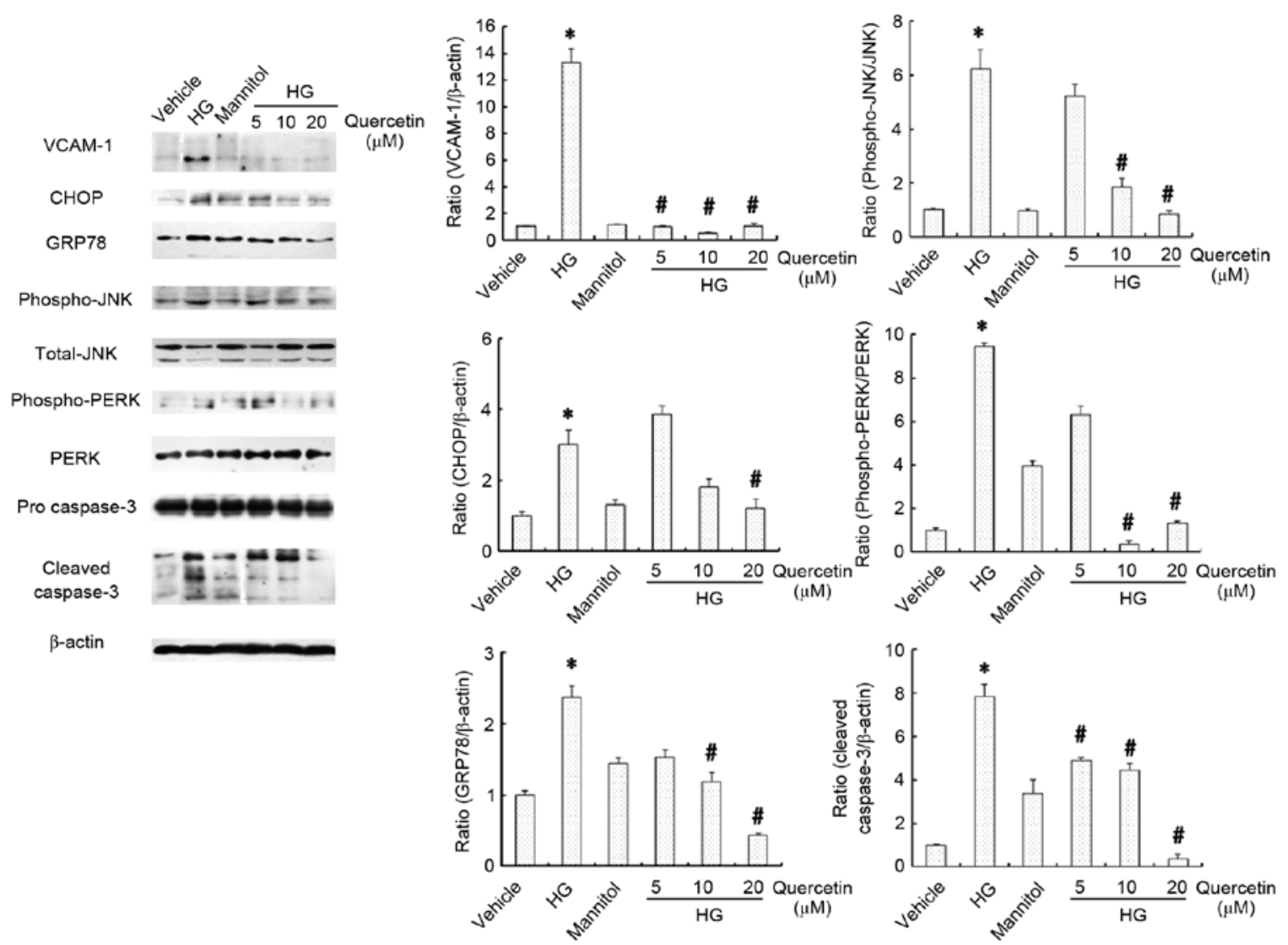

Figure 4. Effects of quercetin on protein expression levels of inflammation, apoptosis and ER stress markers in human umbilical vein endothelial cells cultured in high-dose glucosamine. Protein expression levels were assessed by western blot analysis, with quantification relative to the $\beta$-actin control. Data are presented as the mean \pm standard deviation of 3 replicates. ${ }^{*} \mathrm{P}<0.05$ vs. vehicle group. ${ }^{\#} \mathrm{P}<0.05$ vs. HG group. HG, $15 \mathrm{mM}$ glucosamine; VCAM-1, vascular cell adhesion molecule-1; CHOP, C/EBP homologous protein; GRP78, glucose regulated protein 78; JNK, c-Jun N-terminal kinase; PERK, protein kinase-like ER kinase.

vehicle control. ET-1 expression was significantly decreased compared with the HG group at $20 \mu \mathrm{M}(\mathrm{P}=0.030$; Fig. 3B), and demonstrated no significant difference compared with the vehicle control at all concentrations of quercetin treatment (Fig. 3B). No effect on VCAM-1 expression was observed in response to treatment with $15 \mathrm{mM}$ glucosamine or quercetin compared with the vehicle control (Fig. 3C).
Effects of quercetin on the expression of inflammation, apoptosis and ER stress markers in HUVECs treated with high-dose glucosamine. Inflammation, apoptosis and ER stress in HUVECs was evaluated by assessment of the protein expression levels of VCAM-1, CHOP, GRP78, JNK, PERK and caspase-3 (Fig. 4). No significant differences were observed between the vehicle and mannitol-treated groups 
with respect to these parameters (Fig. 4). Protein expression levels of VCAM-1, CHOP and GRP78 were increased in cells cultured in $15 \mathrm{mM}$ glucosamine compared with the vehicle control group $(\mathrm{P}<0.05$; Fig. 4). Furthermore, the ratios of p-JNK/JNK, p-PERK/PERK and cleaved caspase-3 at 20, 17 and $11 \mathrm{kDa} /$ pro-caspase-3 were also significantly higher in cells cultured in $15 \mathrm{mM}$ glucosamine compared with the vehicle control group $(\mathrm{P}<0.05$; Fig. 4). Treatment with quercetin (particularly 10 and $20 \mu \mathrm{M}$ ) significantly attenuated this effect compared with cells cultured in $15 \mathrm{mM}$ glucosamine ( $\mathrm{P}<0.05$ following treatment with $20 \mu \mathrm{M}$ quercetin; Fig. 4), suggesting that quercetin may protect against ER stress, thus suppressing glucosamine-induced inflammation and apoptosis in HUVECs.

\section{Discussion}

To the best of our knowledge, the present study is the first to report that quercetin ameliorates glucosamine-induced apoptosis and inflammation of HUVECs in vitro. Furthermore, these effects may be partially attributed to the alleviation of ER stress pathways in HUVECs.

Quercetin absorption depends on its form, and its solubility in the vehicle used for administration (42). Quercetin glycoside is the predominant form of quercetin, and the majority of the quercetin metabolites in plasma are sulfate/glucuronide conjugates of quercetin (43). In a study investigating the fate of quercetin, ${ }^{14} \mathrm{C}$-quercetin was administered orally $(100 \mathrm{mg}$, $330 \mu \mathrm{M}$ ) to healthy volunteers (44). The study observed that the oral absorption ranged from 36.4 to $53 \%$, and the biological half-life was 20-72 h. The maximum concentration of quercetin in the plasma of mice has been demonstrated to be $27.6 \mu \mathrm{M}(31)$, however, in certain population studies the highest concentration of quercetin in plasma was $<5 \mu \mathrm{M}(23,38)$. Further studies are, therefore, required to determine the pharmacokinetics of quercetin.

The effect of glucosamine on diabetic AS and osteoarthritis management remains controversial. At a concentration of $5 \mathrm{mM}$ in vitro, glucosamine has been demonstrated to induce insulin resistance (10) and promote pro-apoptotic and pro-inflammatory factors in HUVECs at a concentration of $7.5 \mathrm{mM}$ (45). However, another study showed that glucosamine, up to $20 \mathrm{mM}$, fully protected the chondrocytes from IL-1-induced expression of inflammatory cytokines (46). In vivo studies have demonstrated glucosamine to be both pro- (11) and anti-atherosclerotic (12). In the present study, glucosamine induced apoptosis in HUVECs at a concentration of $15 \mathrm{mM}$, while no significant difference in apoptosis was observed with $15 \mathrm{mM}$ mannitol, an osmolarity control, compared with vehicle. As demonstrated in a previous study, quercetin could effectively inhibit the apoptosis of HUVECs induced by tunicamycin (34). The present study demonstrated that in HUVECs cultured in $15 \mathrm{mM}$ glucosamine, $24 \mathrm{~h}$ treatment with quercetin significantly reduces apoptosis compared with untreated cells. These results demonstrate that quercetin can prevent glucosamine-induced apoptosis, and may represent a novel approach to inhibition of vascular endothelial cell apoptosis in diabetic AS.

Inflammation is an important in the process of AS $(47,48)$. Hyperglycemia induces ICAM-1 and VCAM-1 expression in HUVECs (49); however, Azcutia et al (50) suggested that high levels of extracellular D-glucose alone are not sufficient to promote vascular inflammation. The present study demonstrated that glucosamine significantly elevates ICAM-1 and VCAM-1 protein expression levels. Quercetin has previously been demonstrated to be a powerful anti-inflammatory agent to alleviate AS in vivo (31) and in vitro $(30,51)$. The present study indicated that protein expression levels of ICAM-1 and VCAM-1 were significantly reduced following treatment with quercetin. These data, therefore, suggest that vascular inflammation may be partially due to the elevated glucosamine levels present in patients with diabetes; quercetin may represent an effective, novel therapy to resist HUVECs glucosamine-induced inflammation.

The HBP is associated with vasodilation and the ET-1-induced vasoconstriction response $(52,53)$. HBP activated by excess glucosamine causes endothelial nitric oxide synthase uncoupling to decrease nitric oxide production in isolated mouse aortas, this effect impaired endothelium-dependent relaxations finally (52). Furthermore, ET-1 increases glycosylation with $\beta$-N-acetylglucosamine in vascular smooth muscle cells, which increases vascular contractile responses (53). Both decreased vasodilation, and increased vasoconstriction associated with the HBP, could result in vascular endothelial dysfunction. ET-1 induced glucose uptake dose dependently in neonatal rat cardiomyocytes when cells were cultured in normal medium. However, when cells were cultured in $15 \mathrm{mM}$ glucosamine based on $5 \mathrm{mM}$ glucose, the increased glucose-uptake effect of ET-1 on glucose-uptake was completely abolished (54). The present study demonstrated a significant increase in ET-1 protein expression in cells cultured in $15 \mathrm{mM}$ glucosamine treatment, compared with vehicle. However, treatment of glucosamine-stimulated cells with quercetin, resulted in a significant decrease in ET-1 expression. This suggests that quercetin intervention may improve vascular endothelial dysfunction.

ER stress results in dissociation of GRP78, an ER chaperone protein, from trans-ER-membrane factors, including activating transcriptional factor-6, PERK and inositol requiring enzyme-1. This results in their activation, and the subsequent activation of CHOP, JNK or caspase cascades, causing apoptosis and inflammation (6). Glucosamine has previously been demonstrated to significantly increase GRP78 levels in HUVECs (45). Qiu et al (55) demonstrated that glucosamine-induced ER stress was associated with increased phosphorylation of PERK. JNK is the down-stream effector of ER stress, responsible for induction of apoptosis (56); it also mediates the process between ER stress and inflammation (19). Suganya et al (34) demonstrated that pre-treatment of tunicamycin-stimulated HUVECs with 25 and $50 \mu \mathrm{M}$ quercetin could modulate GRP78 and CHOP levels, reduce expression of B cell lymphoma 2 apoptosis regulator (Bcl-2), increase expression of the pro-apoptotic regulator $\mathrm{Bcl}-2$ associated protein $\mathrm{X}$ apoptosis regulator ( $\mathrm{Bax}$ ) and prevent apoptosis, therefore demonstrating the potential of quercetin to combat ER stress. In the present study, the effects of quercetin that contribute to reduced vascular endothelial cell injury were hypothesized to have a common upstream target: ER stress. This was confirmed by assessment of GRP78 and p-PERK protein expression levels in HUVECs; elevated 
expression of GRP78 and an increased p-PERK/PERK ratio were induced by supplementation with $15 \mathrm{mM}$ glucosamine. Significant increases in CHOP, p-JNK and cleaved caspase-3 expression levels were also observed in cells cultured in $15 \mathrm{mM}$ glucosamine. Treatment with quercetin reduced the expression of GRP78, p-PERK, CHOP, cleaved caspase-3 and p-JNK in glucosamine-supplemented cells, thus restoring ER homeostasis.

Tunicamycin is a typical ER stress inducer by interfering with N-linked protein glycosylation in ER (57). Whether tunicamycin can abolish the beneficial effects of quercetin on glucosamine-induced HUVECs damage remains to be investigate. It can further confirm that the ER stress pathway is involved in the beneficial effects of quercetin on glucosamine-induced HUVECs damage. Although animal studies have demonstrated a maximum concentration of $27.6 \mu \mathrm{M}$ quercetin in mouse plasma (31), human clinical studies have observed a maximum plasma concentration of $5 \mu \mathrm{M}(23,38)$. In the present study, $20 \mu \mathrm{M}$ quercetin was identified as the concentration at which positive effects were observable. As this is likely to be a difficult concentration to achieve in the human diet, further experiments are required to determine a safe and effective quercetin dose in vivo. In addition, further experiments using animal models of diabetic AS and human clinical studies will be essential to further understand the mechanism of action.

In conclusion, the present study suggests that quercetin suppresses the glucosamine-induced inflammatory response and apoptosis in HUVECs, in vitro, and that this effect may be partially due to the inhibition of ER stress. The ER-CHOP and ER-JNK pathways may be involved in the protective effects of quercetin against glucosamine-induced HUVEC injury, and PERK may be a critical factor in the molecular mechanism involved in its protective effects. These results provide further evidence that quercetin may be a potential therapeutic agent for diabetic AS, and ER stress may be one of the possible targets.

\section{Acknowledgements}

The present study was supported by a research grant from the National Natural Science Foundation of China (grant no. 81172652).

\section{References}

1. Juutilainen A, Lehto S, Rönnemaa T, Pyörälä K and Laakso $M$ Type 2 diabetes as a 'coronary heart disease equivalent': An 18-year prospective population-based study in Finnish subjects. Diabetes Care 28: 2901-2907, 2005.

2. Haffner SM, Lehto S, Rönnemaa T, Pyörälä K and Laakso M: Mortality from coronary heart disease in subjects with type 2 diabetes and in nondiabetic subjects with and without prior myocardial infarction. N Engl J Med 339: 229-234, 1998.

3. Han S, Liang CP, DeVries-Seimon T, Ranalletta M, Welch CL, Collins-Fletcher K, Accili D, Tabas I and Tall AR: Macrophage insulin receptor deficiency increases ER stressinduced apoptosis and necrotic core formation in advanced atherosclerotic lesions. Cell Metab 3: 257-266, 2006.

4. Werstuck GH, Khan MI, Femia G, Kim AJ, Tedesco V, Trigatti B and Shi Y: Glucosamine-induced endoplasmic reticulum dysfunction is associated with accelerated atherosclerosis in a hyperglycemic mouse model. Diabetes 55: 93-101, 2006.

5. Marciniak SJ and Ron D: Endoplasmic reticulum stress signaling in disease. Physiol Rev 86: 1133-1149, 2006.
6. Hotamisligil GS: Endoplasmic reticulum stress and atherosclerosis. Nat Med 16: 396-399, 2010.

7. Khan MI, Pichna BA, Shi Y, Bowes AJ and Werstuck GH: Evidence supporting a role for endoplasmic reticulum stress in the development of atherosclerosis in a hyperglycaemic mouse model. Antioxid Redox Signal 11: 2289-2298, 2009.

8. Zhou J, Lhoták S, Hilditch BA and Austin RC: Activation of the unfolded protein response occurs at all stages of atherosclerotic lesion development in apolipoprotein E-deficient mice. Circulation 111: 1814-1821, 2005.

9. Kim AJ, Shi Y, Austin RC and Werstuck GH: Valproate protects cells from ER stress-induced lipid accumulation and apoptosis by inhibiting glycogen synthase kinase-3. J Cell Sci 118: 89-99, 2005.

10. Chen H, Ing BL, Robinson KA, Feagin AC, Buse MG and Quon MJ: Effects of overexpression of glutamine: Fructose-6-phosphate amidotransferase (GFAT) and glucosamine treatment on translocation of GLUT4 in rat adipose cells. Mol Cell Endocrinol 135: 67-77, 1997.

11. Defronzo RA: Insulin resistance, lipotoxicity, type 2 diabetes and atherosclerosis: The missing links. The Claude Bernard Lecture 2009. Diabetologi 53: 1270-1287, 2010.

12. Largo R, Martínez-Calatrava MJ, Sánchez-Pernaute O, Marcos ME, Moreno-Rubio J, Aparicio C, Egido J and Herrero-Beaumont G: Effect of a high dose of glucosamine on systemic and tissue inflammation in an experimental model of atherosclerosis aggravated by chronic arthritis. Am J Physiol Heart Circ Physiol 297: H268-H276, 2009.

13. Rajapakse AG, Ming XF, Carvas JM and Yang Z: O-linked beta-N-acetylglucosamine during hyperglycemia exerts both anti-inflammatory and pro-oxidative properties in the endothelial system. Oxid Med Cell Longev 2: 172-175, 2009.

14. Bao L, Cai X, Zhang Z and Li Y: Grape seed procyanidin B2 ameliorates mitochondrial dysfunction and inhibits apoptosis via the AMP-activated protein kinase-silent mating type information regulation 2 homologue 1-PPAR $\gamma$ co-activator- $1 \alpha$ axis in rat mesangial cells under high-dose glucosamine. Br J Nutr 113: 35-44, 2015.

15. Tabas I and Ron D: Integrating the mechanisms of apoptosis induced by endoplasmic reticulum stress. Nat Cell Biol 13: 184-190, 2011.

16. Sano R and Reed JC: ER stress-induced cell death mechanisms. Biochim Biophys Acta 1833: 3460-3470, 2013.

17. Bahar E, Kim H and Yoon H: ER stress-mediated signaling: Action potential and $\mathrm{Ca}(2+)$ as key players. Int J Mol Sci 17: E1558, 2016.

18. Garg R, Tripathy D and Dandona P: Insulin resistance as a proinflammatory state: Mechanisms, mediators, and therapeutic interventions. Curr Drug Targets 4: 487-492, 2003.

19. Zhang K and Kaufman RJ: From endoplasmic-reticulum stress to the inflammatory response. Nature 454: 455-462, 2008.

20. Ozcan U, Yilmaz E, Ozcan L, Furuhashi M, Vaillancourt E, Smith RO, Görgün CZ and Hotamisligil GS: Chemical chaperones reduce ER stress and restore glucose homeostasis in a mouse model of type 2 diabetes. Science 313: 1137-1140, 2006.

21. Russo M, Spagnuolo C, Tedesco I, Bilotto S and Russo GL: The flavonoid quercetin in disease prevention and therapy: Facts and fancies. Biochem Pharmacol 83: 6-15, 2012.

22. Hertog MG, Kromhout D, Aravanis C, Blackburn H, Buzina R, Fidanza F, Giampaoli S, Jansen A, Menotti A, Nedeljkovic S, et al: Flavonoid intake and long-term risk of coronary heart disease and cancer in the seven countries study. Arch Intern Med 155: 381-386, 1995.

23. Egert S, Bosy-Westphal A, Seiberl J, Kürbitz C, Settler U, Plachta-Danielzik S, Wagner AE, Frank J, Schrezenmeir J, Rimbach G, et al: Quercetin reduces systolic blood pressure and plasma oxidised low-density lipoprotein concentrations in overweight subjects with a high-cardiovascular disease risk phenotype: A double-blinded, placebo-controlled cross-over study. Br J Nutr 102: 1065-1074, 2009.

24. Egert S, Boesch-Saadatmandi C, Wolffram S, Rimbach G and Müller MJ: Serum lipid and blood pressure responses to quercetin vary in overweight patients by apolipoprotein $\mathrm{E}$ genotype. J Nutr 140: 278-284, 2010.

25. Duarte J, Pérez-Palencia R, Vargas F, Ocete MA, PérezVizcaino F, Zarzuelo A and Tamargo J: Antihypertensive effects of the flavonoid quercetin in spontaneously hypertensive rats. $\mathrm{Br}$ J Pharmacol 133: 117-124, 2001. 
26. Juźwiak S, Wójcicki J, Mokrzycki K, Marchlewicz M, Białecka M, Wenda-Rózewicka L, Gawrońska-Szklarz B and Droździk M: Effect of quercetin on experimental hyperlipidemia and atherosclerosis in rabbits. Pharmacol Rep 57: 604-609, 2005.

27. Motoyama K, Koyama H, Moriwaki M, Emura K, Okuyama S, Sato E, Inoue M, Shioi A and Nishizawa Y: Atheroprotective and plaque-stabilizing effects of enzymatically modified isoquercitrin in atherogenic apoE-deficient mice. Nutrition 25: 421-427, 2009.

28. Chuang CC, Martinez K, Xie G, Kennedy A, Bumrungpert A, Overman A, Jia W and McIntosh MK: Quercetin is equally or more effective than resveratrol in attenuating tumor necrosis factor-\{alpha\}-mediated inflammation and insulin resistance in primary human adipocytes. Am J Clin Nutr 92: 1511-1521, 2010.

29. Ortega MG, Saragusti AC, Cabrera JL and Chiabrando GA: Quercetin tetraacetyl derivative inhibits LPS-induced nitric oxide synthase (iNOS) expression in J774A.1 cells. Arch Biochem Biophys 498: 105-110, 2010.

30. Lara-Guzman OJ, Tabares-Guevara JH, Leon-Varela YM, Álvarez RM, Roldan M, Sierra JA, Londoño-Londoño JA and Ramirez-Pineda JR: Proatherogenic macrophage activities are targeted by the flavonoid quercetin. J Pharmacol Exp Ther 343 : 296-306, 2012

31. Kleemann R, Verschuren L, Morrison M, Zadelaar S, van Erk MJ, Wielinga PY and Kooistra T: Anti-inflammatory, anti-proliferative and anti-atherosclerotic effects of quercetin in human in vitro and in vivo models. Atherosclerosis 218: 44-52, 2011.

32. Li YQ, Zhou FC, Gao F, Bian JS and Shan F: Comparative evaluation of quercetin, isoquercetin and rutin as inhibitors of alpha-glucosidase. J Agric Food Chem 57: 11463-11468, 2009.

33. Dai X, Ding Y, Zhang Z, Cai X, Bao L and Li Y: Quercetin but not quercitrin ameliorates tumor necrosis factor-alpha-induced insulin resistance in $\mathrm{C} 2 \mathrm{C} 12$ skeletal muscle cells. Biol Pharm Bull 36: 788-795, 2013.

34. Suganya N, Bhakkiyalakshmi E, Suriyanarayanan S, Paulmurugan R and Ramkumar KM: Quercetin ameliorates tunicamycin-induced endoplasmic reticulum stress in endothelial cells. Cell Prolif 47: 231-240, 2014.

35. Chao CL, Hou YC, Chao PD, Weng CS and Ho FM: The antioxidant effects of quercetin metabolites on the prevention of high glucose-induced apoptosis of human umbilical vein endothelia cells. Br J Nutr 101: 1165-1170, 2009.

36. Zhao B, Zhang Y, Liu B, Nawroth P and Dierichs R: Endothelial cells injured by oxidized low density lipoprotein. Am J Hematol 49: 250-252, 1995.

37. Yao S, Sang H, Song G, Yang N, Liu Q, Zhang Y, Jiao P, Zong C and Qin S: Quercetin protects macrophages from oxidized low-density lipoprotein-induced apoptosis by inhibiting the endoplasmic reticulum stress-C/EBP homologous protein pathway. Exp Biol Med (Maywood) 237: 822-831, 2012.

38. Larson A, Witman MA, Guo Y, Ives S, Richardson RS, Bruno RS, Jalili T and Symons JD: Acute, quercetin-induced reductions in blood pressure in hypertensive individuals are not secondary to lower plasma angiotensin-converting enzyme activity or endothelin-1: Nitric oxide. Nutr Res 32: 557-564, 2012.

39. Ding Y, Zhang ZF, Dai XQ and Li Y: Myricetin protects against cytokine- induced cell death in RIN-m5f $\beta$ cells. J Med Food 15: 733-740, 2012

40. Djoba Siawaya JF, Roberts T, Babb C, Black G, Golakai HJ, Stanley K, Bapela NB, Hoal E, Parida S, van Helden P and Walzl G: An evaluation of commercial fluorescent bead-based luminex cytokine assays. PLoS One 3: e2535, 2008.
41. Matěj R, Smětáková M, Vašáková M, Nováková J, Sterclová M, Kukal J and Olejár T: PAR-2, IL-4R, TGF- $\beta$ and TNF- $\alpha$ in bronchoalveolar lavage distinguishes extrinsic allergic alveolitis from sarcoidosis. Exp Ther Med 8: 533-538, 2014.

42. Kelly GS: Pantothenic acid. Monograph. Altern Med Rev 16: 263-274, 2011

43. Azuma K, Ippoushi K, Ito H, Horie H and Terao J: Enhancing effect of lipids and emulsifiers on the accumulation of quercetin metabolites in blood plasma after the short-term ingestion of onion by rats. Biosci Biotechnol Biochem 67: 2548-2555, 2003.

44. Walle T, Walle UK and Halushka PV: Carbon dioxide is the major metabolite of quercetin in humans. J Nutr 131: 2648-2652, 2001.

45. Fiorentino TV, Procopio T, Mancuso E, Arcidiacono GP, Andreozzi F, Arturi F, Sciacqua A, Perticone F, Hribal ML and Sesti G: SRT1720 counteracts glucosamine-induced endoplasmic reticulum stress and endothelial dysfunction. Cardiovase Res 107: 295-306, 2015.

46. Gouze JN, Gouze E, Popp MP, Bush ML, Dacanay EA, Kay JD, Levings PP, Patel KR, Saran JP, Watson RS and Ghivizzani SC: Exogenous glucosamine globally protects chondrocytes from the arthritogenic effects of IL-1beta. Arthritis Res Ther 8: R173, 2006.

47. Ross R: Atherosclerosis-an inflammatory disease. N Engl J Med 340: 115-126, 1999.

48. Lusis AJ: Atherosclerosis. Nature 407: 233-241, 2000.

49. Altannavch TS, Roubalová K, Kucera P and Andel M: Effect of high glucose concentrations on expression of ELAM-1, VCAM-1 and ICAM-1 in HUVEC with and without cytokine activation. Physiol Res 53: 77-82, 2004.

50. Azcutia V, Abu-Taha M, Romacho T, Vázquez-Bella M, Matesanz N, Luscinskas FW, Rodríguez-Mañas L, Sanz MJ, Sánchez-Ferrer CF and Peiró C: Inflammation determines the pro-adhesive properties of high extracellular d-glucose in human endothelial cells in vitro and rat microvessels in vivo. PLoS One 5: e10091, 2010.

51. Panicker SR, Sreenivas P, Babu MS, Karunagaran D and Kartha CC: Quercetin attenuates Monocyte Chemoattractant Protein-1 gene expression in glucose primed aortic endothelial cells through NF-kappaB and AP-1. Pharmacol Res 62: 328-336, 2010.

52. Wu Z, Xiong $\mathrm{Y}$, Gajanayake $\mathrm{T}$, Ming XF and Yang Z: p38 Mitogen-activated protein kinase is required for glucosamine-induced endothelial nitric oxide synthase uncoupling and plasminogen-activator inhibitor expression. Circ J 76: 2015-2022, 2012

53. Lima VV, Giachini FR, Carneiro FS, Carvalho MH, Fortes ZB, Webb RC and Tostes RC: O-GlcNAcylation contributes to the vascular effects of ET-1 via activation of the RhoA/Rho-kinase pathway. Cardiovasc Res 89: 614-622, 2011.

54. Wu-Wong JR, Berg CE and Dayton BD: Endothelin-stimulated glucose uptake: Effects of intracellular $\mathrm{Ca}(2+)$, cAMP and glucosamine. Clin Sci (Lond) 103: 418S-423S, 2002.

55. Qiu W, Su Q, Rutledge AC, Zhang J and Adeli K: Glucosamine-induced endoplasmic reticulum stress attenuates apolipoprotein B100 synthesis via PERK signaling. J Lipid Res 50: 1814-1823, 2009.

56. Urano F, Wang X, Bertolotti A, Zhang Y, Chung P, Harding HP and Ron D: Coupling of stress in the ER to activation of JNK protein kinases by transmembrane protein kinase IRE1. Science 287: 664-666, 2000

57. Xu C, Bailly-Maitre B and Reed JC: Endoplasmic reticulum stress: Cell life and death decisions. J Clin Invest 115: 2656-2664, 2005. 